\title{
trabalhonecessário
}

issn: $1808-799 X$

ano 7 - número 9 - 2009

\section{A FORMAÇÃO DO GRANDE CAPITAL BRASILEIRO NO SETOR DA INDÚSTRIA DE CONSTRUÇÃO: RESULTADOS PRELIMINARES DE UM ESTUDO SOBRE CAUSAS E ORIGENS}

Pedro Henrique Pedreira Campos - phpcampos@yahoo.com.br

Resumo: A economia brasileira hoje tem como uma de suas áreas mais dinâmicas e desenvolvidas a indústria de construção. Contando com uma escala nacional e presença internacional consolidada, as empresas do setor de construção pesada detêm um oligopólio no tocante ao mercado de grandes obras realizadas no país. O presente estudo busca hipóteses explicativas das causas e origens da existência de empresas tão poderosas nesse tipo de atividade. Nesse sentido, o estudo da organização dessas empresas e a presença de seus representantes no interior do aparelho de Estado, bem como o exame das políticas públicas específicas parecem ser pontos-chave para a compreensão dessa marca da economia brasileira atual.

Palavras-chave: indústria de construção; empreiteiras; construtoras; história de empresas; história econômico-social 


\section{trabalhonecessário \\ issn: $1808-799 \mathrm{X}$ \\ ano 7 - número 9 - 2009}

\section{A formação do grande capital brasileiro no setor da indústria de construção: resultados preliminares de um estudo sobre causas e origens}

Pedro Henrique Pedreira Campos

O ano de 1830 marca um dos episódios mais significativos dos conflitos entre as diferentes formas de capital. Naquele ano, a católica e relativamente atrasada Bélgica se tornava independente da Holanda em um conflito direto e aberto entre o capital industrial, então ascendente na Bélgica, a partir do impulso da barreira protecionista representada pelo bloqueio continental napoleônico, contra o capital de circulação, comercial e financeiro, dominante na poderosa Holanda, de Roterdã e Amsterdã, grandes centros comerciais e financeiros que ainda quase rivalizavam com Londres. A disputa nesse momento tomou contornos militares e a vitória da burguesia industrial belga levou à independência do país e da imposição de uma política industrializante, responsável pela criação da segunda potência fabril da Europa em meados do século. A antes vigorosa Holanda, com a insistência na manutenção de políticas livre-cambistas e não-protecionistas, por conta de todos os interesses liberalizantes da grande finança e do grande comércio, só viria a se industrializar na segunda metade do XIX, de maneira tímida e não-sistemática, sendo esse novo setor industrial fortemente subsumido ao ainda dominante capital vigente na circulação e no financiamento ${ }^{1}$.

Estudaremos nesse artigo não um caso de conflito entre diferentes funções e frações do capital, mas um exemplo de fortalecimento do capital funcionante produtor de mais-valia pelo setor bancário e financeiro. Trata-se de uma situação em que o capital bancário serviu de firme suporte para a consolidação de uma forma específica de capital industrial através de políticas de juros e pagamento altamente convidativas. A grande engenharia brasileira, como tentaremos mostrar, tornou-se o que é, em boa parte, graças a políticas de financiamento significativamente acolhedoras.

Pode-se dizer que a indústria de construção é hoje um dos setores mais consolidados e com empresas poderosas da economia brasileira. Apesar de não viver mais a febre de

\footnotetext{
${ }^{1}$ HOBSBAWM, Eric J. O caso holandês. In: As Origens da Revolução Industrial. São Paulo: Global, 1979. p. 57-75; LANDES, David S. Prometeu Desacorrentado: transformação tecnológica e desenvolvimento industrial na Europa Ocidental, de 1750 até os dias de hoje. $2^{\text {a }}$ ed. Rio de Janeiro: Elsevier, 2005. p. 150-184.
} 
issn: $1808-799 \mathrm{X}$

ano 7 - número 9 - 2009

encomendas numerosas dos anos 70, e também 50 e 60, as empresas de construção pesada conseguiram estabelecer um oligopólio naquele campo, fazendo com que seis empresas multinacionais controlem as grandes obras no país, seguidas por outro grupo seleto de firmas que se associam a essas companhias ou arrematam obras de menor porte. Essas empreiteiras, surgidas por volta dos anos 40 e fortalecidas com as grandes obras criadas nas décadas seguintes, iniciaram um eficiente processo de internacionalização a partir do período do "milagre". Nos anos 80 e 90, com a nova configuração econômica e política, com menor número de compras por parte do Estado e com os processos de desestatização e terceirização de serviços públicos, essas construtoras, para permanecerem grandes empresas, ramificam suas atividades dando atenção especial às concessões públicas e às empresas privatizadas. Isso faz com que os conglomerados atuais da Odebrecht, Andrade Gutierrez, Camargo Corrêa e Queiroz Galvão conservem como área minoritária de atividade a indústria de construção. Assim, o grupo Odebrecht é sócio majoritário e controlador da maior firma latino-americana de petroquímica, a Braskem, responsável por 71,5\% das suas receitas em $2007^{2}$; o grupo AG divide atualmente com a família Jereissati o controle da maior empresa de telecomunicações do subcontinente, a nova Broi, fruto da fusão da antiga Brasil Telecom e da Tele Norte-Leste, Telemar e Oi, o que corresponde a mais de 50\% dos negócios do conglomerado da família Andrade $^{3}$; o grupo criado por Sebastião Camargo Penteado é um dos maiores conglomerados industriais paulistas, com investimentos em têxteis, calçados, aço (a Usiminas), instituições financeiras (a Itaúsa), cimento, dutos industriais e outros, dentre os quais a empreiteira representa apenas a empresa que deu origem ao complexo empresarial e que hoje tem importância relativamente diminuta no grupo ${ }^{4}$; a Queiroz Galvão é outra investidora em siderurgia, bancos, agronegócio, seleção genética de embriões bovinos, perfuração de poços petrolíferos, construção naval e outros negócios ligados a petróleo e gás 5 . Uma análise dos processos de internacionalização e ramificação dessas companhias foi feita em um trabalho

\footnotetext{
${ }^{2}$ O Globo. Caderno O País. Informe publicitário. Edição de 30 de abril de 2008. p. 12-3.

${ }^{3}$ Em um caderno especial lançado na imprensa para comemorar os 60 anos do grupo, apesar de o texto se referir basicamente à história da empresa no ramo de construção, quatro das cinco propagandas presentes no encarte, feitas por empresas fornecedoras de produtos e serviços ao grupo AG, eram do setor de telecomunicações. Vide O Globo. Projetos de marketing. Caderno especial AG 60 anos. Edição de 09 de dezembro de 2008.

${ }^{4}$ Ver http://www.camargocorrea.com.br/ acessado em 20 de agosto de 2007.

${ }^{5}$ Informações retiradas do sítio http://www.queirozgalvao.com/br/ acessado em 30 de agosto de 2007.
} 
issn: 1808-799X

ano 7 - número 9 - 2009

anterior $^{6}$ e não será repetida aqui, sendo só importante a menção do fenômeno para que se perceba que se trata de grandes multinacionais no ramo da construção, além de grandes conglomerados empresariais, dentro dos quais o papel de empreiteiras não é mais o único, tampouco o dominante.

Nem sempre o país dispôs de um grupo seleto de poderosas empresas no ramo da indústria de construção. No século XIX e no início do XX, a maior parte das grandes obras e dos empreendimentos de grande complexidade técnica eram realizados por empresas estrangeiras, que dominavam o ramo da construção pesada nacional. Grandes obras hidráulicas, hidrelétricas, ferrovias, rodovias e construções urbanas mais complexas eram feitas por companhias forenses, que dispunham de um quadro de técnicos bem montado sem rival no mercado nacional.

Com a emergência do grupo político de Vargas ao poder e, principalmente, com a ruptura significada pelo golpe do Estado Novo, o capital privado nacional passa a ter representação privilegiada no aparelho estatal e passa a ser beneficiado diretamente por políticas que fortalecerão empresas do setor, dando início à criação de um grande capital em alguns ramos industriais ${ }^{7}$.

Nesse contexto, houve um dos primeiros casos em que uma empresa nacional arrematou uma obra de infra-estrutura de grande porte. No final dos anos 30, a firma Dahne, Conceição \& Cia realizava as obras da adutora Riberão das Lages, que vem a ser uma grande obra de abastecimento de água que inclui uma rede de estradas de rodagem com mais de 100 km para caminhões, a instalação de uma usina para construção de tubos e a realização da obra da adutora em si, construção grandiosa que servia para regularizar o serviço de abastecimento de água para a cidade do Rio de Janeiro, antes à mercê de pequenas adutoras que não garantiam um suprimento contínuo. O problema é que o controle da obra pela empresa gerou conflitos com capitais internacionais há muito estabelecidos no país, que denunciavam os "lucros fabulosos" da empreitada e a utilização de um empréstimo do Banco do Brasil, o que teria sido um financiamento privilegiado para a empresa de Frederico Dahne. Esse defendeu dos ataques em uma carta direta para o presidente da República:

\footnotetext{
${ }^{6}$ Ver CAMPOS, Pedro Henrique Pedreira. As origens da internacionalização das empresas de engenharia brasileiras. In: História \& Luta de Classes. $\mathrm{n}^{\circ}$ 6. De certa forma, o presente artigo é uma continuação daquele.

7 Ver MENDONÇA, Sônia Regina de. Estado e Economia no Brasil: opções de desenvolvimento. Rio de Janeiro: Graal, 1985. p. 13-38.
} 


\title{
trabalnđnecessário \\ issn: $1808-799 X$ \\ ano 7 - número 9 - 2009
}

\begin{abstract}
Têm sido terrivel e incessante Snr. Presidente, a campanha contra nós movida, pelos nossos concorrentes, e sobretudo por empresas e bancos estrangeiros que não querem aceitar e nem se conformam, que uma firma composta de técnicos brasileiros, com capital levantado no Paiz, pudesse realisar obras que até agora só a empresas e técnicos estrangeiros eram confiadas, e sempre com financiamentos onerossimos para o Brasil. Essa campanha, aparada por alguns organs de imprensa $[\ldots]^{8}$
\end{abstract}

Por mais que se possa enxergar aí as origens da formação do grande capital da construção nacional, não se deve reduzir o debate acima exposto a uma mera questão nacional. Trata-se muito mais de um conflito entre capitais privados que, no âmbito do discurso, das difamações, das campanhas na imprensa e no nível do convencimento, traveste-se de uma disputa nacional. Vê-se aí mais um conflito entre empresas que, independente de sua origem, buscam a realização dessas grandes obras, o lucro e o financiamento privilegiado do Estado. Inclusive, o período e a política dominante voltada para o capital nacional então vigente assumiram a aparência de uma política de Estado nacionalista, o que deve ser visto pelo historiador na sua dimensão de construção ideológica ${ }^{9}$.

São desse período também as primeiras políticas de financiamento habitacional de grande porte postas em prática por organismos como os institutos de aposentadorias e pensões de industriários e comerciários, a Fundação Casa Popular e a própria Caixa Econômica Federal, tão importantes para a consolidação do setor de construção civil urbana instalado no país. Durante a campanha presidencial de 1950, as equipes de Eurico Gaspar Dutra e Getúlio Vargas trocaram acusações sobre qual governo havia criado maior número de unidades habitacionais. Em um panfleto, o grupo de Dutra acusava Getúlio de ter feito apenas 12.305 "casas populares" em 15 anos de governo, enquanto Dutra teria criado 41.313 em seus quatro anos à frente da presidência ${ }^{10}$. Em seguida, em um discurso de $1^{\circ}$ de maio, Vargas afirmou que pretendia construir 30 mil casas populares ao longo de sua gestão ${ }^{11}$. Por mais que se deva duvidar frontalmente dos dados e do conceito de 'casa popular' presentes no panfleto e no discurso, é plausível afirmar que tinham início então as políticas de financiamento imobiliário

\footnotetext{
${ }^{8}$ Centro de Pesquisa e Domcumentação de História Contemporânea do Brasil (doravante, CPDOC-FGV). Arquivo Getúlio Vargas (GV). Correspondência. RJ. 4f. Referência: GV c 1939.12.05.

${ }^{9}$ Para discussões a esse respeito, ver CERQUEIRA, Eli Diniz; BOSCHI, Renato Raul. Empresariado Nacional e Estado no Brasil. Rio de Janeiro: Forense Universitária, 1978. p. 45-107, dentre outros.

${ }^{10}$ CPDOC-FGV. Arquivo Getúlio Vargas (GV). Correspondência. RJ. 1f. Referência: GV c 1949/1950.00.00/2.

${ }^{11}$ CPDOC-FGV. Arquivo Getúlio Vargas (GV). Correspondência. RJ. 6f. Referência: GV c 1950/1953.00.00/2.
} 


\section{frabalhonecessário \\ issn: $1808-799 X$ \\ ano 7 - número 9 - 2009}

em massa por organismos estatais, mecanismo muito relevante para a criação do grande capital na construção imobiliária nacional. Ainda, em uma correspondência do presidente do Instituto de Aposentadorias e Pensões dos Industriários (IAPI), Gabriel Pedro Moacyr, com Lourival Fontes, de 1952, era alertado um motivo adicional para a construção de imóveis. Segundo o interlocutor do presidente do IAPI, “[a] construção de casas para vendas aos associados é um privilégio contra o comunismo, pois dá ao associado o sentido de propriedade." 12

O caso de uma adutora ou de obras de engenharia civil não podem ser comparadas em complexidade técnica a trabalhos realizados para a construção de hidrelétricas ou grandes unidades industriais. O fortalecimento paulatino do capital nacional que se viu em outros setores também ocorreu no tocante a essas obras até que o Brasil detivesse empresas líderes na construção de usinas hidrelétricas e barragens no mercado mundial. As primeiras centrais geradoras de energia elétrica a partir da força da água no Brasil foram feitas por empresas estrangeiras ou então com forte demanda de capital e tecnologias vindas do exterior. A Light foi uma das primeiras empresas a investir no ramo, levantando barragens principalmente no rio Paraíba. Entre 1899 e 1901, construía a central de Parnaíba, no rio Tietê, e depois construiria as hidrelétricas de Ilha dos Pombos, em 1924, Fontes Novas, em 1940, Santa Cecília, em 1952, Vigário, também em 1952, Nilo Peçanha, no ano seguinte, e Pereira Passos, no ano de $1962^{13}$.

A primeira grande hidrelétrica nacional, Paulo Afonso I, levantada entre os anos de 1948 e 1952, ficou sob a responsabilidade direta da nova estatal Chesf (Companhia Hidrelétrica do Vale do São Francisco) e teve participação significativa de técnicos, equipamentos e tecnologia vindos de outros países. As turbinas e os geradores das usinas são elementos que, mesmo com o fortalecimento ulterior das empresas de construção nacionais, continuaram, nas grandes hidrelétricas brasileiras, sob a responsabilidade de grandes empresas internacionais do ramo elétrico, como Westinghouse, General Eletric, Siemens, Brown Boveri, Schneider, Hitachi, Voith e até da soviética Leningradsky Metallichesky Zavo

\footnotetext{
${ }^{12}$ CPDOC-FGV. Arquivo Getúlio Vargas (GV). Correspondência. RJ. 2f. Referência: GV c 1952.02.04/2.

${ }^{13}$ Dados obtidos no endereço eletrônico http://www.lightrio.com.br/ acessado dia 28 de janeiro de 2009.
} 


\section{Itrabalhonecessário \\ issn: $1808-799 \mathrm{X}$ \\ ano 7 - número 9 - 2009}

na barragem de Sobradinho $^{14}$, construída no período da chamada política externa independente do período Geisel.

A primeira grande central hidrelétrica construída por uma empresa de origem nacional é a de Furnas, no rio Grande, em Minas Gerais, levantada como parte do Plano de Metas de JK. A construtora Mendes Júnior anuncia essa obra como momento-chave para a consolidação e nacionalização da empresa e afirma que "[a]través desse projeto, a Mendes Júnior mudou a visão de que apenas as grandes construtoras estrangeiras eram capazes de executar obras daquele porte, abrindo caminho para outras empresas de engenharia do Brasil." 15 Por mais que haja no texto um tom de auto-elogio no tocante ao pioneirismo da construtora, dali para a frente outras empresas nacionais passariam a levantar usinas hidrelétricas.

A partir de então, as grandes usinas de eletricidade nacionais seriam construídas por empresas de origem brasileira, que teriam cada vez mais dinamismo técnico para dominar as diversas fases e etapas desse tipo de construção. Assim, na construção da usina de Itaipu, a maior em atividade do mundo ainda hoje, com um valor de US\$ 14 bilhões no período, teve presença dominante de empresas brasileiras, apesar do consórcio que a ergueu ter sido internacional. Segundo a apresentação institucional da empresa binacional, "[n]o domínio da construção civil, escavações e obras civis, a Itaipu atingiu um nível de nacionalização [...] de praticamente $100 \%$. Na área de fabricação e montagem de equipamentos, o índice de nacionalização nunca foi inferior a $85 \% ", 16$.

Também outros setores da construção pesada sofreram um processo de nacionalização paulatina e foram agregando experiência às grandes construtoras nacionais, até que elas fossem exportadoras de tecnologia. É o caso dos trens metropolitanos, que só começaram a ser construídos no Brasil bem tardiamente, nos anos 70. Apesar dessa defasagem, as mesmas empreiteiras brasileiras participaram da construção dos metrôs das grandes metrópoles brasileiras para depois construir trens metroviários em várias capitais sul-americanas e em Lisboa. Assim, segundo a apresentação da Companhia do Metropolitano de São Paulo, a linha

\footnotetext{
${ }^{14}$ Informações presentes no endereço eletrônico http://www.chesf.gov.br/ acessado dia 27de janeiro de 2009.

${ }^{15}$ Citação presente no endereço eletrônico http://www.mendesjunior.com.br/ acessado em 20 de agosto de 2007.

${ }^{16}$ Dados obtidos no endereço eletrônico http://www.itaipu.gov.br/ acessado em 28 de janeiro de 2009.
} 


\section{Itrabalhonecessário \\ issn: $1808-799 \mathrm{X}$ \\ ano 7 - número 9 - 2009}

1 do metrô da cidade, construída a partir de 1969, teve um "nível de nacionalização da ordem de 70\%", enquanto a linha 3, que começou a operar em 1979, teve um índice de $95 \%{ }^{17}$.

Novamente, deve-se tomar cuidado com o termo um tanto vago, 'nível de nacionalização', que diz respeito à quantidade de encomendas feitas a empresas de origem nacional ou com sede direta no país. Não se trata aqui de apontar um 'desenvolvimento' nacional ou fortalecimento da 'economia nacional', mas sim do amadurecimento do capital privado de origem nacional do setor de construção, que diversifica as suas atividades em um país fortemente marcado pelo transporte rodoviário - tanto na integração nacional como nas áreas urbanas - e se consolida técnica e tecnologicamente em setores antes dependentes da importação de projetos, equipamentos e conhecimento de empresas de origem forânea.

Mais do que todas as obras supracitadas, o tipo de construção de grande porte que mais tinha a marca da realização por empresas estrangeiras no passado brasileiro é o das ferrovias. Durante todo o século XIX e início do XX, o sistema ferroviário nacional foi implantado com a presença decisiva de empresas, tecnologias, projetos, capital e até administração de empresas de origem extra-nacional, notavelmente as inglesas. Porém, durante a ditadura, grandes projetos ferroviários, associados à extração mineral e à indústria, foram realizadas pelas grandes da engenharia nacionais, como a estrada de ferro de Carajás e a ferrovia do Aço.

Dessa forma, nos diversos setores e tipos de atividade da construção pesada, incluindo obras de grande complexidade, as empresas fundadas no Brasil, auxiliadas por políticas favoráveis, desenvolveram um quadro técnico próprio e dominaram tecnologias específicas, conseguindo se consolidar como firmas de escala nacional e com fôlego para competir com empresas multinacionais em mercados em geral periféricos, como é o caso da América do Sul e da África. Cabe entender agora como isso ocorreu em cada caso individual.

Apesar de as cinco gigantes do setor de construção pesada serem hoje companhias consolidadas que atuam em diversos segmentos da construção, com presença internacional marcante, elas tiveram suas peculiaridades no processo de amadurecimento e ascensão nacional, fenômeno que se deve, entre outros motivos, à origem regional diferenciada das empresas, à adoção de diferentes estratégias por parte de seus administradores e em função das conexões políticas e sociais estabelecidas pelos empresários e gerentes das companhias.

\footnotetext{
${ }^{17}$ Informação obtida no endereço eletrônico http://www.metro.sp.gov.br/ acessado em 29 de janeiro de 2009. 
issn: 1808-799X

ano 7 - número 9 - 2009

Cada caso deve ser analisado individualmente para que se perceba o contraste na formação de cada uma delas e para que se compreenda a hierarquia atual e a relativa especialização ainda existente.

A Odebrecht é hoje a maior das construtoras nacionais e foi fundada por Norberto Odebrecht em 1943, em Salvador. Sua trajetória foi altamente alavancada por obras estaduais e regionais, no que devem ter sido importantes os laços políticos estabelecidos com líderes baianos e nordestinos. Pesa em favor das empreiteiras nordestinas o fato que o potencial hidrelétrico da região é o mais explorado do país e que elas foram muitas vezes escaladas para participar de grandes obras desse tipo, notavelmente nas grandes usinas presentes no rio São Francisco e contratadas pela Companhia Hidrelétrica do São Francisco (Chesf). Outro ponto favorável para as construtoras da região foi a implementação da Sudene, que trouxe obras de infra-estrutura, inclusive as obras contra a seca, e instalações industriais para o Nordeste. Nesse sentido, a Norberto Odebrecht parece ter aproveitado de maneira altamente eficiente essas oportunidades, construindo diversas instalações industriais no Nordeste, que marcam o período inicial da empresa, fazendo obras portuárias no rio São Francisco e, emblematicamente, o próprio prédio-sede da Sudene em Recife. Se todas as companhias de construção guardam certa especialização em alguns tipos de empreendimento, as edificações industriais marcam o início da atuação da empreiteira baiana, sendo a área mais marcante das atividades da Odebrecht o petróleo e todos os serviços de engenharia prestados à Petrobrás. A construção da primeira refinaria da estatal coube à Odebrecht e diversas obras vieram em seguida, como perfurações de poços, o edifício-sede no Rio, plataformas, dutos, estradas e outros. A especialização da companhia no setor é tão vigorosa que direcionou a própria ramificação da empresa ainda em fins dos anos 70, quando ela começou a comprar ações de unidades industriais da subsidiária de petroquímica da Petrobrás, a Petroquisa ${ }^{18}$.

Se a Norberto Odebrecht tem a marca do petróleo em sua história, o contrário se pode dizer da mineira Andrade Gutierrez, fundada em 1948 em Belo Horizonte, que não tem em seu currículo nenhuma plataforma, com parcas obras para a Petrobrás e no ramo petrolífero. A Andrade Gutierrez pode ser considerada uma companhia que se adaptou bastante ao modelo de transporte e de energia nacional, sendo as obras mais visíveis em sua trajetória as rodovias e as usinas hidrelétricas. A especialização em obras rodoviárias é tão forte para a construtora

\footnotetext{
${ }^{18}$ Informações obtido no endereço eletrônico http://www.odebrecht.com.br/ acessado em 19 de agosto de 2007. 
issn: $1808-799 \mathrm{X}$

ano 7 - número 9 - 2009

que, passados 20 anos do início da internacionalização da empresa, a maioria absoluta de suas obras no exterior é de estradas e obras rodoviárias urbanas. Emergente durante o Plano de Metas, quando conseguiu a sua primeira obra para além do estado de Minas com a BR-3 que ligava o Rio de Janeiro à capital de Minas Gerais. A Andrade Gutierrez participou da construção das rodovias Pedro I, Castelo Branco, Manaus-Porto Velho, dos Bandeirantes, dos Trabalhadores - atual rodovia Ayrton Senna - e do rodoanel Mário Covas. Marcada por diversas associações em sua história, a empresa estabeleceu parcerias com a antes arqui-rival da Odebrecht e com a Camargo Corrêa, para a construção das grandes e avançadas estradas estaduais paulistas ${ }^{19}$.

A paulista Camargo Corrêa tem uma das mais poderosas trajetórias dentre as cinco gigantes da engenharia nacional, tendo participado das maiores obras realizadas no século $\mathrm{XX}$ no Brasil. Itaipu, ponte Rio-Niterói, Belém-Brasília, Transamazônica, o metrô paulista e o feito incrível de ter construído sozinha a usina hidrelétrica de Tucuruí, a $4^{\mathrm{a}}$ maior do mundo, fazem da empresa talvez a que tem o percurso mais presente entre os grandes empreendimentos feitos durante a vigência das obras ditas faraônicas. A cidade de Brasília sofreu terraplanagem, pavimentação, ligações rodoviárias, a construção da barragem do Paranoá e até o abastecimento alimentício foi assegurado pela empresa na época da sua criação. A empresa Novacap convidou a empreiteira paulista para construir na nova capital o Moinho de Trigo Jauense, antiga área de atuação de Sebastião Camargo. A construção de estradas em São Paulo e a ramificação precoce são outras marcas da companhia, que tem associação com as empresas de Antonio Ermírio de Moraes e com o banco Bradesco e que é a construtora mais aberta a parcerias com empresas estrangeiras, traço pouco marcante nas outras empreiteiras e geralmente visível apenas nos seus empreendimentos fora do setor da construção. A Camargo Corrêa emerge a partir de obras rodoviárias e aeroviárias no interior de São Paulo, sendo uma das mais diversificadas e menos especializadas das construtoras, com menos atividades, porém, nas construções portuárias e de saneamento ${ }^{20}$.

A Mendes Júnior já foi a maior construtora brasileira e não por pouco tempo. A empresa é profundamente marcada pelo Plano de Metas, tendo erguido diversos empreendimentos do projeto de Juscelino e se especializado exatamente nas áreas priorizadas

\footnotetext{
${ }^{19}$ http://www.andradegutierrez.com.br/ acessado em 20 de agosto de 2007.

20 http://www.camargocorrea.com.br/ acessado em 20 de agosto de 2007.
} 
issn: $1808-799 \mathrm{X}$

ano 7 - número 9 - 2009

pelo plano qüinquienal: hidrelétricas, rodovias e obras ligadas à Petrobrás. Os contatos com JK e sua equipe são antigos e remetem ao período da criação da empresa, de 1953, quando os membros da família Mendes Júnior eram amigos pessoais de assessores do presidente. Algumas obras de destaque são a estrada Belém-Brasília, o memorial da América Latina, o aeroporto internacional de Confins, a refinaria de Paulínia, além do metrô de São Paulo e do Rio de Janeiro. Com todo o dinamismo adquirido no período, tornou-se a primeira multinacional brasileira do ramo de construção, saindo do país em 1969 para empreendimentos na América do Sul. A empreiteira acumulou problemas de pagamento de seus projetos bilionários com o governo de Saddam Hussein, no Iraque. Mas provavelmente o grande engano da empresa foi não ter seguido a tendência de diversificação e ramificação feito por todas as outras quatro grandes nos anos $80 \mathrm{e}$, principalmente, nos 90, quando a construção pesada rendia apenas uma fração do que proporcionara na década de $70^{21}$. Assim, mantendo-se como uma construtora 'puro sangue', sem grandes marcas de diversificação de negócios, tendo apenas uma pequena siderúrgica em Minas Gerais, a empresa logrou se tornar uma das menos expressivas construtoras do grupo das cinco gigantes da construção pesada ${ }^{22}$.

A quinta e última dentre as cinco grandes multinacionais brasileiras da indústria de construção é a menor dentre elas, apesar de constituir um conglomerado econômico digno de nota. A Queiroz Galvão, empresa pernambucana de 1953, tem, assim como a Odebrecht, a marca dos projetos da Sudene e da Petrobrás no Nordeste em seu momento de alavancagem. Não tem uma presença muito destacada na construção de hidrelétricas e não emplaca grandes obras sozinhas, sendo muitas vezes associada minoritária à outra grande empresa do ramo quando arremata um projeto de grande porte. O traço mais destacável de sua especialização é o grande número de obras para a Petrobrás ou para empresas associadas à estatal, estando hoje ela presente na perfuração de poços e na construção naval. A internacionalização da empresa é um tanto definhada quando comparada às suas congêneres, reduzindo-se basicamente a rodovias realizadas na América do Sul. Alguns projetos emblemáticos foram as rodovias Fernão Dias, Rio-Santos, Cuiabá-Porto Velho, e estrada de ferro Carajás, a ferrovia do Aço e a urbanização da Praça XV, no Rio de Janeiro ${ }^{23}$.

\footnotetext{
${ }^{21}$ Para se ter uma idéia do pique de obras durante o "milagre" e o II PND, a potência instalada do país cresce 2,5 vezes entre 1973 e 1982, segundo a www.eletrobras.gov.br/ visitado no dia 26 de janeiro de 2009.

${ }^{22} \mathrm{http}: / /$ www.mendesjunior.com.br/ acessado em 20 de agosto de 2007.

${ }^{23} \mathrm{http} / / / \mathrm{www}$.queirozgalvao.com/br/ acessado em 30 de agosto de 2007.
} 
issn: 1808-799X

ano 7 - número 9 - 2009

São comuns também as associações entre essas empresas ou de alguma(s) delas(s) com outras menores para tocar grandes projetos. Assim, uma parceria comum de empresas que antes eram ásperas concorrentes é o da Norberto Odebrecht e da Andrade Gutierrez para construção de hidrelétricas nas regiões do rio Tocantins e Madeira. Outra associação ocorrida é entre Andrade Gutierrez e Camargo Corrêa no controle da Companhia de Concessões Rodoviárias (CCR), empresa de concessões rodoviárias. A Queiroz Galvão se associou à Carioca para administrar o serviço de abastecimento de água de municípios fluminenses. As grandes obras também contam com a participação de várias empresas que geralmente dividem a construção por acordo ou, quando determinado pelo edital, em diferentes lotes. Assim, no caso da usina de Itaipu participaram a Andrade Gutierrez, Camargo Corrêa, Mendes Júnior e a Companhia Brasileira de Projetos e Obras (CBPO), empresa depois adquirida pela Odebrecht. Da mesma forma, da construção da Transamazônica participaram Queiroz Galvão, Camargo Corrêa, Andrade Gutierrez e outras. Observar associações entre a baiana Odebrecht e a paulista Camargo Corrêa é um pouco mais difícil ao longo da trajetória das duas, dada a grande concorrência pela liderança e por grandes projetos realizadas entre as duas companhias $^{24}$.

Se as cinco gigantes do setor de construção pesada podem ser considerados um oligopólio no setor por deterem uma fatia dominante do mercado, elas não estão ou nem sempre estiveram sozinhas no ramo, sendo acompanhadas por empresas nacionais de médio a grande porte que não têm uma atuação internacional expressiva ou nunca tiveram qualquer obras realizada no exterior. Essas são OAS, Constran, CR Almeida, Carioca Engenharia e Santa Bárbara, companhias que ou arrematam obras menos lucrativas ou participam de consórcios com alguma(s) das cinco gigantes para tocar grandes obras, ou ainda foram grandes empresas e não participam mais do rol das maiores do país.

Esse último caso parece ter como exemplo a Constran, empresa de propriedade de Olacyr Francisco de Moraes, que já foi uma das maiores empreiteiras brasileiras, responsável por hidrelétricas no Mato Grosso, pelo metrô paulistano, obras de saneamento no estado e pelas grandes estradas paulistas, como a via Anchieta, a rodovia dos Imigrantes e outras. Apesar do grande porte nos anos 70 e 80, não teve uma expressão nacional homogênea, sendo

24 http://www.odebrecht.com.br/; http://www.andradegutierrez.com.br/; http://www.camargocorrea.com.br/; http://www.mendesjunior.com.br/; http://www.queirozgalvao.com/br/ 
issn: 1808-799X

ano 7 - número 9 - 2009

suas obras concentradas principalmente nos estados de São Paulo e Mato Grosso. Só chegou a ter uma pequena obra no exterior, de uma adutora na Costa Rica e teve o privilégio de ser a realizadora de diversos empreendimentos das gestões de Paulo Salim Maluf à frente da prefeitura e do governo de São Paulo, como o projeto Cingapura e outros. A empresa entra em uma crise profunda quando propõe a construção da estrada de ferro Ferronorte, que ligaria o Centro-Oeste produtor de soja e outros produtos ao porto de Santos e à malha ferroviária do Sudeste. Segundo o acordo com o governo paulista, a empresa de Olacyr de Moraes construiria a ferrovia e o governo estadual a ponte ferroviária sobre o rio Paraná. As gestões de Quércia e Fleury no estado não concluíram a obra, só realizada no período FHC/Covas, o que levou o empresário à bancarrota. $\mathrm{O}$ antigo rei da soja e o brasileiro mais jovem a chegar a US\$ 1 bilhão parece estar hoje falido e suas fazendas no Mato Grosso foram recentemente vendidas para o Incra para efeito de reforma agrária. A Constran, ramo da indústria de construção do conglomerado Itamarati - pertencente ao empresário -, não figura mais entre as grandes empresas brasileiras do setor, segundo o seu próprio dono, em função da nova conjuntura econômica e política surgida nos anos 90: "Os investimentos em infra-estrutura no Brasil pararam. O que nós temos de bom na Constran é o acervo tecnológico. Mas perdemos o bonde das privatizações e dos pedágios." Hoje em dia, Moraes sofre arresto de bens e foge de seus credores ${ }^{25}$.

A CR Almeida é uma empresa paranaense de 1958, fundada pelos irmãos Cecílio do Rego Almeida e Félix do Rego Almeida, trilhou o caminho similar ao das outras empreiteiras e é hoje um grupo econômico que reúne mais de 30 empresas com valor de mercado de aproximadamente $\mathrm{R} \$ 9,4$ bilhões. Também marcadamente regional, concentrou esforços nas rodovias e grandes hidrelétricas no Paraná e estados vizinhos, detendo um número reduzido de obras fora desse perímetro. Algumas obras grandiosas foram as hidrelétricas de São Simão, Ita, Segredo, Estreito e outras, o trem metropolitano de Porto Alegre, a ferrovia central do Paraná, a rodovia Porto Velho-Rio Branco e o edifício-sede da Eletrosul, em Florianópolis. Além de não ter uma expressão claramente nacional, não aferiu nenhuma obra fora do país. A ramificação foi realizada desde os anos 70, quando o grupo adquiriu a Britanic Indústria

\footnotetext{
${ }^{25}$ Informações obtidas nas seguintes fontes: http://www.constran.com.br/ acessado em 30 de agosto de 2007; http://www.terra.com.br/istoedinheiro/365/economia/olacyr.htm acessado dia 03 de fevereiro de 2009; http://www.folha.com.br/ acessado em 03 de fevereiro de 2009.
} 
issn: 1808-799X

ano 7 - número 9 - 2009

Química, do ramo de explosivos, tendência que se acentuou nos anos 90, com as concessões rodoviárias no estado a partir da empresa Ecorodovias ${ }^{26}$.

Outra companhia de expressão marcadamente regional é a Carioca Engenharia. Criada em 1947 pelo engenheiro João Carlos Backheuser, no Rio de Janeiro, incorporou, em 1988, a também carioca Christiani Nielsen Engenheiros e Construtores, adquirindo relevância nacional como especialista em certos setores e associada a empresas maiores. Trata-se de uma companhia voltada em especial para obras de urbanização, ramo menos rentável do setor, tendo em seu porta-fólio obras como a ampliação atual do aeroporto Santos Dumont, obras do projeto de despoluição da Baía de Guanabara, o autódromo Nelson Piquet, a via Light, a Linha Vermelha, o estádio do Maracanã, a praça da Apoteose, a Cidade da Música e o complexo presidiário de Bangu, todas no Rio de Janeiro. Provavelmente, as suas maiores obras na atualidade são o arco rodoviário do Rio de Janeiro e a Companhia Siderúrgica do Atlântico, em que presta serviços de engenharia e construção para a alemã ThyssenKrupp. Realizadora de muitas obras no governo Brizola, foi responsável pela construção pela construção de 140 CIEPs no estado, sendo a construtora, posteriormente, do projeto similar dos CEUs, da prefeitura de São Paulo. O nível de especialização da firma é provavelmente o mais acentuado dentre as construtoras, não tendo ela nenhuma hidrelétrica em sua trajetória e sendo possivelmente a principal empresa nacional na construção de portos, obras de saneamento e emissários submarinos, com realizações desse tipo de obra em Fortaleza, Maceió, Sergipe, Guarujá, Praia Grande e Rio de Janeiro. Não possui nenhuma obra no exterior e realizou também um processo de ramificação, atuando nos setores de saneamento e abastecimento de água, através das companhias Águas de Niterói, Águas do Imperador e outras, ficando responsável pelo suprimento de água potável em quase todo o interior do estado do Rio em associação com outros grupos ${ }^{27}$.

Por fim, Santa Bárbara e OAS são empresas que já têm uma expressão nacional, mas permanecem muito enraizadas aos seus estados de origem, Minas e Bahia respectivamente. A pouca disponibilização de informações dificulta uma análise mais detida, mas elas tendem a entrar em grandes empreendimentos como empresas associadas a construtoras maiores, não sendo líderes de consórcios. Um exemplo disso é o da linha 4 do metrô de São Paulo, que tem

\footnotetext{
${ }^{26} \mathrm{http}: / / \mathrm{www} . c r a l m e i d a . c o m . b r /$ acessado dia 03 de fevereiro de 2009.

${ }^{27} \mathrm{http}$ ///www.cariocaengenharia.com.br/ acessado dia 04 de fevereiro de 2009.
} 
issn: $1808-799 \mathrm{X}$

ano 7 - número 9 - 2009

participação da baiana OAS. Essa empresa novata, fundada em 1976, já tem algumas obras no exterior e a Santa Bárbara, criada em 1967, não seguiu ainda esse caminho ${ }^{28}$.

A relativa especialização das companhias brasileiras de engenharia é visível através de uma observação sumária no conjunto das obras realizadas por cada uma delas. Porém, boa parte desse foco foi em geral imposta pela própria trajetória das políticas públicas postas em prática ao longo da história brasileira. Assim, se a energia hidrelétrica foi privilegiada na composição da matriz energética nacional e se o transporte rodoviário foi sobre-valorizado em relação a outras formas de sistemas logísticos, isso influiu diretamente no desenvolvimento das empreiteiras, na sua ramificação e internacionalização. Contabilizando as obras no exterior das cinco gigantes da construção pesada, vê-se que elas participaram da construção de apenas 4 ferrovias e de um total de 22 obras rodoviárias em mercados fora do país. Da mesma forma, segundo o levantamento parcial realizado na pesquisa, enquanto nenhuma delas construiu uma termoelétrica em outros países, foram erguidas ou tiveram assessoramento técnico um total de 15 usinas hidrelétricas em mercados diferenciados, como Chile, Angola, Estados Unidos, China e outros ${ }^{29}$. A marca dos modelos viário e energético nacionais ficam ainda mais evidentes quando se vê o posicionamento da maior construtora nacional, a Norberto Odebrecht - a única brasileira a figurar na lista -, no ranking elaborado pela Engineering News Record para o ano de 2006. Enquanto a empresa é listada como a maior construtora de hidrelétricas do mundo, ela figura apenas como a $11^{\mathrm{a}}$ no índice geral de energia, que conta hidroeletricidade e outras formas de geração de energia e como $57^{\mathrm{a}}$ maior empreiteira do mundo. De forma similar, ela surge como $9^{\text {a }}$ construtora do ramo de transporte em massa e ferrovias, deficiência do sistema viário brasileiro, e $7^{\mathrm{a}}$ no ranking de rodovias ${ }^{30}$.

Para compreender todo esse processo de monopolização, conglomeração e investimentos no exterior, é preciso levar em conta a organização das empresas em aparelhos privados de hegemonia e sua penetração, via associações ou via empresa, no interior do aparelho de Estado $^{31}$. À luz dessas informações e desses cruzamentos, fica mais claro entender todas as políticas voltadas para o setor e todas as obras maiúsculas realizadas em

\footnotetext{
${ }^{28}$ http://www.oas.com.br/ acessado em 20/08/07; http://www.santabarbarasa.com.br/ acessada em 30/08/07.

${ }_{29}$ http://www.odebrecht.com.br/; http://www.andradegutierrez.com.br/; http://www.camargocorrea.com.br/; http://www.mendesjunior.com.br/; http://www.queirozgalvao.com/br/.

${ }^{30}$ Dados presentes no sítio da companhia http://www.odebrecht.com.br/ acessado em 19 de agosto de 2007.

${ }^{31}$ A organização das empresas em agências e sua penetração no aparelho de Estado será tema de um outro artigo.
} 
issn: $1808-799 \mathrm{X}$

ano 7 - número 9 - 2009

certos períodos da história nacional. Dentre esses, o período da ditadura, entre 1964 e 1985, parece constituir um momento-chave para a compreensão do processo de consolidação e internacionalização dos grupos empresariais analisados, em função das políticas altamente favoráveis ao setor.

Em primeiro lugar, deve ser ressaltado o financiamento. Com o golpe de 64, o BNDE, antes criado com o objetivo primordial de financiar as estatais criadas pelo governo, passa a abrir o leque de sua carteira de empréstimos, passando a privilegiar as empresas privadas, principalmente no setor de infra-estrutura. Muitas vezes, também, além da receita com o PIS e o PASEP a partir das reestruturações que deram o pretenso caráter social ao BNDE'S', lançase mão da tomada de empréstimos junto a bancos internacionais com taxas de juros e de câmbio voláteis para financiar empreendimentos no país a juros fixos, sem o perigo das alternâncias nos juros e na taxa cambial, ou melhor, o risco do empréstimo que chega até o capital privado é retido no $\mathrm{BNDES}^{32}$. Da mesma forma, logo após o golpe, foi criado o BNH, instrumento do governo que utilizava a arrecadação com o FGTS e poupança voluntária para financiar o capital imobiliário nacional ${ }^{33}$. Com as reformulações ocorridas na empresa estatal ao longo da década de 70, ela passou a custear também obras de urbanização, saneamento e infra-estrutura $^{34}$. Além disso, o Banco do Brasil e a Caixa Econômica Federal permaneciam como financiadores do capital privado em certos setores e situações específicas.

A criação, o funcionamento e a reorientação do BNDE, do BNH e, em menor escala, do $\mathrm{BB}$ e da $\mathrm{CEF}$, podem ser considerados uma vitória do capital industrial no Brasil, e da indústria de construção em particular, incluindo aí tanto a construção civil como a pesada. Apesar dos contextos distintos vigentes durante a ditadura e das políticas diferenciadas encampadas pelos dois órgãos, seus financiamentos ao setor, quase sempre com juros abaixo dos praticados no mercado e em alguns casos até negativos, fizeram com que o capital da indústria de construção 'invertesse' a lógica do capital financeiro clássico, como foi analisado por Rufold Hilferding ${ }^{35}$, em que há uma prevalência do capital bancário sobre o capital

\footnotetext{
${ }^{32}$ Ver BRANDÃO, Rafael Vaz da Motta. ABDIB e a Política Industrial do Governo Geisel, 1974-1979. Texto apresentado ao laboratório Polis. Niterói: 2007. p. 1-22.

${ }^{33}$ Para uma análise do BNH, ver FONTES, Virgínia. Rupturas e Continuidades na Política Habitacional Brasileira, 1920-79. Dissertação de mestrado. Niterói: UFF/ICHF/PPGHIS, 1986. passim.

${ }^{34}$ Um exemplo foi o emissário submarino de Ipanema, construído em meados dos anos 70 e financiado pelo BNH; vide http://www.cedae.rj.gov.br/ visitado dia 26 de janeiro de 2009.

${ }^{35}$ HILFERDING, Rufold. O Capital Financeiro. São Paulo: Nova Cultural, 1985. passim.
} 
issn: $1808-799 \mathrm{X}$

ano 7 - número 9 - 2009

industrial. Com essas instituições bancárias públicas, as empresas de construção não se subordinaram ao capital bancário, mas fizeram-no subserviente aos seus próprios interesses, ao fazer com que suas próprias demandas fossem atendidas nas decisões e políticas praticadas por esses bancos. Isso foi obtido a partir da participação de representantes do setor da construção nos órgãos de decisão dessas instituições financeiras ou então nas instâncias burocráticas hierarquicamente superiores às mesmas ${ }^{36}$. As construtoras ficaram, assim, livres da possibilidade de, parcial ou totalmente, quedarem dependentes ou ficarem alçadas ao poder de bancos privados nacionais ou, principalmente, estrangeiros. Esse mecanismo reduziu a quantidade de mais-valia retida no âmbito financeiro da reprodução de capital, potencializando os lucros do setor funcionante do capital, no caso a indústria de construção, o que maximizou a própria acumulação do setor e constituiu um dos fatores que possibilitou a formação de um capital monopolista no ramo da construção nacional. Tudo isso deve ser explicado pelo amplo poder de organização, penetração e barganha dos empresários do ramo nas relações de poder inerentes ao Estado brasileiro, principalmente no período em questão ${ }^{37}$.

O mecanismo de subsídio financeiro às grandes construtoras com tarifas e condições altamente benéficas não é, no entanto, uma especificidade apenas do período ditatorial. No governo Lula, é possível observar a política de financiamento da exportação de serviços de engenharia através do BNDES e do Banco do Brasil, o que inclusive gerou um imbróglio nas relações diplomáticas com o Equador recentemente ${ }^{38}$. Da mesma forma, a Caixa Econômica foi e é financiadora do setor de construção imobiliária, área de atividade de todas as grandes empresas da construção pesada, nos períodos anterior e posterior à existência do Banco Nacional de Habitação ${ }^{39}$.

Além do financiamento privilegiado, outro fator-chave que permite a compreensão da monopolização das empresas do setor foi uma política específica posta em prática durante a ditadura. Quando da construção do pólo petroquímico do Rio Grande do Sul, realizado entre 1976 e 1983, o responsável pela obra, o engenheiro da Petrobrás Percy Louzada de Abreu narra uma dificuldade encontrada para a compra de equipamentos e contratação de serviços:

\footnotetext{
${ }^{36}$ Veremos alguns exemplos adiante.

${ }^{37}$ Parauma análise dessas formas de organização, ver CAMPOS, Pedro Henrique Pedreira. As origens... op. cit.

${ }^{38}$ Ver http://www.oglobo.com.br/ acessado em 17 de fevereiro de 2009.

${ }^{39}$ Ver CPDOC-FGV. Arquivo GV. Correspondência. RJ. 6f. Referência: GV c 1950/1953.0.00/2.
} 


\title{
trabalhonecessário \\ issn: $1808-799 \mathrm{X}$ \\ ano 7 - número 9 - 2009
}

\begin{abstract}
No embate com fornecedores de todo o tipo para reduzir custos, um dos grandes problemas que enfrentávamos era a obrigatoriedade de usar equipamento nacional, sempre que houvesse produção no país. Era a lei da similaridade, um dos dispositivos da reserva de mercado, base da política de substituição de importações. Além de tarifas proibitivas de importações, os empresários brasileiros ainda tinham mais esse obstáculo no caso de financiamento por bancos oficiais. Se houvesse similar nacional, era obrigatória a sua utilização [grifo nosso]. ${ }^{40}$
\end{abstract}

Segundo Abreu, essa medida fazia com que fossem comprados produtos às vezes $80 \%$ mais caros do que os disponíveis no comércio internacional.

Porém, o trecho não se refere à encomenda de serviços de engenharia às construtoras. Em um capítulo posterior, ele cita a confusão gerada por um empréstimo do BID para a realização do terminal logístico do pólo. Assim como o Banco Mundial, o Banco Interamericano obriga a abertura de uma concorrência internacional para a realização de seus empréstimos.

\begin{abstract}
Essa exigência era totalmente inaceitável, sob todos os aspectos. Como trazer empresas estrangeiras para uma obra que não dependia de qualquer tecnologia ou equipamento que não fossem de pleno domínio das empresas nacionais? Certamente, nem a lei brasileira, que estabelecia a reserva de mercado, permitia isso. Politicamente, nem pensar. O governo nos daria um corridão [sic] se chegássemos com essa proposta. Mais ainda, como nós, pessoas físicas, circularíamos nos meios da engenharia fazendo um papelão desses num momento em que as companhias brasileiras tinham escassez de serviço? Não tivemos alternativa que dizer ao BID que era inaceitável atender a esse quesito porque entraríamos em conflito com a engenharia nacional [grifo nosso]. ${ }^{41}$
\end{abstract}

Portanto, durante a ditadura, a lei da reserva de mercado protegia as empresas nacionais da concorrência estrangeira, o que explica o fato de que todas as grandes obras nacionais implementadas no país tenham sido feitas por companhias de origem nacional. Aliado ao financiamento privilegiado, essa é uma outra forma de proteção ao capital privado nacional.

Porém, mais um fator se agrega a esses dois. Durante a ditadura, os órgãos de imprensa sofriam diversas formas de censura, a justiça tinha limitações impostas pelo regime e todas as formas de transparência, denúncia e investigação estavam não neutralizadas, mas drasticamente limitados no que diz respeito a processos ilegais em editais, contratação, pagamento e realização de obras e outros empreendimentos. Sendo o Estado o cliente

\footnotetext{
${ }^{40}$ ABREU, Percy Louzada de. A Epopéia da Petroquímica no Sul: história do pólo de Triunfo. Florianópolis: Expressão, 2007. p. 153-62.

${ }^{41}$ ABREU, Percy Louzada de. A Epopéia da Petroquímica no Sul. op. cit. p. 213-33.
} 
issn: $1808-799 \mathrm{X}$

ano 7 - número 9 - 2009

privilegiado das empresas ora em questão, essa limitação surtiu o efeito de estimular uma série de processos irregulares e ilegais na construção de obras.

Apesar de ser difícil estudar casos de corrupção no período exatamente por conta do silêncio forçado imposto aos órgãos fiscalizadores tradicionais, alguns escândalos de tão abusivos vieram à tona em alguns meios de divulgação ou já foram investigados anteriormente por outros pesquisadores. Um exemplo de publicidade de um escândalo é o do coronel Raymundo Saraiva Martins, ex-adido militar na embaixada brasileira em Paris, que fez uma denúncia pública no ano de 1976, que só veio à tona em 1984. Segundo a acusação, o então embaixador brasileiro na França, Antônio Delfim Netto teria cobrado US\$ 6 milhões em propina para ser depositado em um banco suíço de fornecedores franceses para compra de equipamentos de hidrelétricas. A compra seria para alguma usina hidrelétrica em construção no Brasil naquele momento, possivelmente Tucuruí, que era parcialmente financiada por bancos franceses. A investigação foi enterrada pelo Serviço Nacional de Informações (SNI) no período ${ }^{42}$.

Outro caso conhecido foi o da construção das usinas nucleares. A central de Angra I, construída com tecnologia norte-americana e equipamentos elétricos da Westinghouse foi erguida por um consórcio liderado pela Odebrecht. Da mesma forma, a usina de Angra II, fruto do Acordo Brasil-Alemanha de 'cooperação nuclear' também foi arrematado pela companhia apesar de não ter tido qualquer processo de licitação. Após a assinatura do contrato entre a empreiteira e o Ministério de Minas e Energia, o então diretor da empresa, Ângelo Calmon de Sá, dela demitiu-se para assumir um cargo no Ministério na vaga de Severo Gomes. Em seguida, no mesmo ano de 1977, foi assinado um último contrato complementar do MME, assinado por Calmon de Sá, com a empresa habilitando-a a apresentar custos suplementares sem qualquer limitação de verbas ${ }^{43}$.

Esse caso ilustra como as empresas e suas associações não podem ser analisadas como instituições separadas do Estado, mas presentes no interior de órgãos específicos e com representação muitas vezes permanente no aparelho estatal. As conexões políticas também sempre foram muito importantes para a vitória em licitações e a obtenção de bons contratos

\footnotetext{
42 O GLOBO. Caderno Rio. Obituário de Raymundo Saraiva Martins. Edição de 05 de agosto de 2008. p. 19.

43 BRANDÃO, Rafael Vaz da Motta. O Negócio do Século: o acordo de cooperação nuclear Brasil-Alemanha. Dissertação de mestrado. Niterói: UFF/ICHF/PPGHIS, 2008. p. 72-107.
} 
issn: $1808-799 \mathrm{X}$

ano 7 - número 9 - 2009

por parte das construtoras. Assim como a Constran aferiu diversas obras na gestão Maluf e não conseguiu uma obra relativamente pequena nos dois mandatos do governo estadual de Quércia e Fleury, a OAS é um caso emblemático e conhecido de empresa com relações íntimas com titulares do aparelho de Estado. O fundador da empresa, César Mata Pires teve a sorte de se casar com a filha do líder político baiano Antonio Carlos Magalhães. Por conta da importância das encomendas dos governos de ACM e seus aliados na Bahia para a empresa, a companhia recebeu das ruas o sugestivo apelido de 'Obras Arranjadas pelo Sogro, ${ }^{44}$. Os empreendimentos estaduais fizeram o fortalecimento da firma no final da ditadura e, com a sobrevida política do ex-líder da UDN e ARENA e de seu grupo na Nova República, a empresa se consolidou com as obras no estado até se tornar uma empresa nacional e com obras no exterior.

A própria história da formação da Odebrecht e toda a sua relação significativa com a Petrobrás tiveram lances de articulação política e envolvimento com titulares de cargos públicos e eletivos. O engenheiro já citado Percy Abreu, ao fazer um breve histórico da petroquímica no Brasil, cita a construção do primeiro pólo petroquímico nacional de Landulpho Alves, em Mataripe, Bahia: "Foi uma decisão estratégica apoiada em vários argumentos técnicos, mas principalmente políticos”. Apesar de não citar que o primeiro presidente da empresa foi o líder político regional Juracy Magalhães, tão importante no governo ditatorial, Abreu lembra que apesar de, naquele momento - início dos anos 60 -, 90\% da produção nacional ser na Bahia, 10\% da demanda nacional de petroquímicos estava no estado. Argumentava-se desconcentração industrial, "[n]o entanto, deve ter pesado o fato de boa parte dos técnicos de maior hierarquia da Petrobrás serem baianos natos ou com grande afinidade com aquele estado." ${ }^{45}$ No final das contas, a Odebrecht foi incumbida de construir a refinaria Landulpho Alves (Relan), juntamente com a Mendes Júnior ${ }^{46}$ e, a partir de então, a empreiteira baiana conseguiria contratos contínuos com a estatal petrolífera que, naquele momento, concentrava suas encomendas na região Nordeste.

Também antes do período ditatorial, as relações entre membros de companhias privadas com burocratas e funcionários de instituições estatais foram importantes para o

\footnotetext{
${ }^{44}$ GASPARI, Elio. Coluna. Caderno O País. In: O Globo. Edição de 16 de março de 2008. p. 13.

${ }^{45}$ ABREU, Percy Louzada de. A Epopéia da Petroquímica no Sul. op. cit. p. 46.

${ }^{46}$ Informações obtidas nos sítios da http://www.odebrecht.com.br/ e da http://www.mendesjunior.com.br/
} 
issn: $1808-799 \mathrm{X}$

ano 7 - número 9 - 2009

soerguimento de outros grupos. Hoje, o nome Furnas diz respeito à subsidiária da Eletrobrás no Sudeste, empresa pública muito ligada ao grupo Odebrecht, mas o nome surgiu da empresa, também pública, criada para administrar a usina hidrelétrica no rio Grande que entrava em operação no início dos anos 60. No centro de memória da empresa de energia elétrica, é exposta em estilo anedótico a forma como foi dado o pontapé inicial para o projeto da usina: "Conta a história que foi o engenheiro da Cemig Francisco Noronha quem descobriu as Corredeiras das Furnas, quando saiu para pescar a convite da família Mendes Júnior. Era sabido que a Cemig já procurava no Rio Grande um lugar ideal para construir uma usina." ${ }^{47}$ Novamente, vê-se a importância da penetração dos grupos empresariais no aparelho de Estado através de relações com técnicos burocráticos. Nesse caso, a construtora mineira daria início à construção da primeira grande central hidrelétrica realizada por uma empresa de origem nacional.

Com o fim da ditadura, as relações ditas incestuosas entre empreiteiras e membros do aparelho de Estado não teriam fim, estando essas empresas envolvidas nos principais escândalos de corrupção que emergem continuamente desde a redemocratização. Para a construção da hidrelétrica de Xingó, a quarta maior do país, a partir de 1987, os empresários Emílio Odebrecht, Olacyr de Moraes, da Constran, e Murilo Mendes, da Mendes Júnior, montaram a empresa Xingó Ltda sob a liderança do grupo Odebrecht. Segundo reportagem da Folha de São Paulo, de 1999, essa nova empresa foi acusada de depositar o equivalente a R \$ 1 milhão nas contas de Paulo César Farias nos primeiros anos da década de 1990. Logo em seguida, a Odebrecht venceria o processo de privatização das empresas de petroquímica PPH (Companhia Industrial de Polipropileno), Poliolefinas, CPC (Companhia Petroquímica de Camaçari) e Salgema no Programa Nacional de Desestatização do governo Collor, empresas que depois reunidas levariam o grupo a criar a Braskem ${ }^{48}$. Essa sorte especial que as empreiteiras contaram nesses momentos foram essenciais para que elas se tornassem fortes como são e para que elas realizassem com eficiência os processos de ramificação e internacionalização. No entanto, as denúncias fariam com que a empreiteira baiana fosse a

\footnotetext{
${ }^{47}$ Trecho retirado do endereço eletrônico http://www.furnas.com.br/ acessado dia 27 de janeiro de 2009.

${ }^{48} \mathrm{http}: / / \mathrm{www}$ 2.paulohenriqueamorim.com.br/ acessado em 20 de janeiro de 2009.
} 
issn: $1808-799 \mathrm{X}$

ano 7 - número 9 - 2009

protagonista da CPI dos Anões do Orçamento, realizada no Congresso no início dos anos $90^{49}$.

As empresas de construção figuram ainda como grandes financiadoras de grupos e partidos políticos, estabelecendo suas relações com diversos blocos de poder e defendendo uma política de obras de infra-estrutura e combate à austeridade fiscal, no que eles se opõem em muitos momentos com os neoliberais e os setores financistas. Com o financiamento das campanhas, as construtoras demandam posteriormente dos parlamentares fidelidade e voto em projetos que lhes são importantes, como se vê na reportagem a seguir, publicada no jornal: "Derrotada na licitação para a usina de Jirau, a empreiteira Norberto Odebrecht mobiliza sua bancada na Câmara para levar o presidente da Aneel, Jerson Kelman, e a ministra Dilma Rousseff a depor na Comissão de Minas e Energia."

O apoio e o financiamento que as empresas de construção fazem a certos grupos políticos não implica um posicionamento político e ideológico rígido. São as mesmas empreiteiras brasileiras envolvidas com a ditadura brasileira, com a ditadura de Augusto Pinochet no Chile, com o Iraque de Saddam Hussein que vão atuar na Angola de Agostinho Neto ou na Venezuela de Hugo Chavéz atualmente. A Norberto Odebrecht, por exemplo, foi considerada pelo presidente venezuelano uma "empresa amiga" classificada como de "absoluta confiança" que o capital não tem uma filiação política estática, sendo essa altamente modelável conforme a possibilidade de lucro.

As próprias associações setoriais muitas vezes são utilizadas não para objetivos estritamente políticos, mas para acordos e combinações irregulares entre empresários. Recentemente, descobriu-se uma prática de cartel no ramo de cimento, em que atuam os grupos Camargo Corrêa, Vorantim, Holcim e outros. O veículo utilizado pelos empresários para combinar preços, quantidade de produção e divisão de mercado era a própria Associação Brasileira da indústria de Cimento, a Abesc ${ }^{52}$.

Todas essas formas de corrupção ou fenômenos similares não podem ser vistos como acidentes de percurso nas trajetórias dessas empresas. Muito pelo contrário, contratos

\footnotetext{
${ }^{49}$ O Globo. Coluna de Ricardo Noblat. Edição de 21 de maio de 2007. p. 4.

${ }^{50}$ O Globo. Coluna de Elimar Franco. Edição de 10 de julho de 2008. p. 2.

${ }^{51} \mathrm{http}: / /$ www.oglobo.com.br/ acessado em 17 de fevereiro de 2009.

52 O Globo. Caderno de Economia. Edição de 09 de março de 2007.
} 


\title{
trabalnonecessário \\ issn: $1808-799 X$ \\ ano 7 - número 9 - 2009
}

corruptos e fraudados foram instrumentos de importância dificilmente questionáveis para o fortalecimento das empresas de construção. Eles não podem ser vistos como desvios ou pior ainda, em uma perspectiva moralizante comumente adotada no âmbito do senso comum, como um crime apenas dos servidores envolvidos na ilicitude, os corruptos, sem que a culpa recaia sobre os corruptores, que no caso são as empreiteiras: se PC Farias foi preso por crime de corrupção, longe ficou a possibilidade de prender Emílio Odebrecht ou outro empresário envolvido no escândalo da Xingó Ltda. A corrupção não é um acidente, um desvio, nem um defeito, mas parte da lógica da política de Estado posta em prática, que tende a beneficiar certas frações do capital, no caso, justamente aquela com amplo poder de organização e penetração no aparelho estatal. É ainda mais uma forma de competição entre capitais, uma maneira de uma empresa garantir a vitória sobre uma rival na concorrência sem a necessidade prévia de possuir uma superioridade técnica ou financeira sobre a companhia adversária.

\section{Conclusão: em vias de uma explicação}

Voltando ao tema das industrializações no século XIX, dentre as muitas perspectivas existentes sobre a Revolução Industrial britânica, o entendimento de Tom Kemp faz saltar os olhos:

\begin{abstract}
Na Grã-Bretanha, a industrialização não foi resultado de um projecto ou de um programa preestabelecidos. Resultou unicamente das operações de uma boa série de firmas comerciais competitivas que, espontaneamente, procuraram defender os seus próprios interesses, num clima e num quadro institucional extremamente favoráveis a um funcionamento integral e livre das forças do mercado. Essa natureza orgânica e autónoma da industrialização britânica constitui a sua característica mais original e notável. ${ }^{53}$
\end{abstract}

O trecho do historiador econômico anglo-saxão deixaria feliz os membros da escola escocesa se esses fossem vivos, mas historicamente deve ser relegado para o nível do mito. Isso porque não se pode pensar a industrialização inglesa sem levar em conta as tarifas proibitivas impostos aos tecidos indianos pela Coroa britânica, a já então secular política estatal de incentivo à marinha mercante, as guerras feitas com a Holanda para dominar rotas e vias comerciais, ou melhor, não se pode deixar de lado a questão central do Estado.

\footnotetext{
${ }^{53}$ KEMP, Tom. A Revolução Industrial na Europa do Século XIX. Lisboa: Edições 70, 1987. p. 20.
} 
issn: $1808-799 \mathrm{X}$

\section{ano 7 - número 9 - 2009}

De forma similar, quando se analisa a formação da grande engenharia brasileira representada pelas cinco gigantes da construção pesada, não se pode pensar que essa foi uma obra puramente privada, impulsionada de forma exclusiva ou mesmo preponderante por sistemas de gestão arrojados, política empresarial de incentivo à tecnologia ou estratégia institucional eficiente dos entes privados. Toda análise da formação do capital monopolista no setor de construção não pode prescindir da questão central do Estado e das políticas públicas.

Embora não seja o único determinante da criação do oligopólio dos conglomerados na indústria de construção, foi através do Estado que as empresas adquiriram sistemas de financiamentos privilegiados e seguros, políticas de reserva de mercado que impediam a concorrência do grande capital estrangeiro, além de condições institucionais para enorme acumulação de capital que poucos sistemas políticos que não um regime ditatorial benéfico ao grande capital poderia proporcionar.

A questão poderia ser colocada de outra forma tendo a mesmo resposta: como entender que a Camargo Corrêa, a construtora do grande capital industrial e bancário de São Paulo não seja hoje a líder no ramo de construção pesada e na transnacionalização, perdendo a posição para uma empresa de origem periférica e de consolidação e estabelecimento de escala nacional posterior? Novamente, a resposta não pode ser encontrada apenas em estratégias privadas ou explicações técnicas e administrativas, devendo ser compreendida a partir das conexões políticas e capacidade de organização e penetração no aparelho de Estado. Os laços com lideranças políticas baianas, as relações estabelecidas no interior da Petrobrás e todo o trânsito livre criado dentro do Itamaraty são a chave para o entendimento do processo de monopolização da empreiteira baiana, que hoje é a $44^{\mathrm{a}}$ maior construtora do mundo e a mais internacionalizada de todas as empresas brasileiras, juntamente com a siderúrgica Gerdau. Assim, para compreender o estágio alcançado pela grande engenharia brasileira como em todo e em particular, faz-se necessário estudar o Estado em um sentido amplo, ou melhor, analisar o "produto da permanente inter-relação entre sociedade civil e sociedade política", entendendo-se por sociedade civil as empresas privadas e suas formas de organizações em associações e por sociedade política o Estado em sentido restrito, o aparelho estatal.

Em 2008, no leilão para a construção da segunda hidrelétrica do rio Madeira, após a vitória do consórcio liderado pela Odebrecht e constituído também pela Andrade e por Furnas no primeiro leilão, pôde-se ver um fruto da força da industrialização belga. $\mathrm{O}$ consórcio 
issn: $1808-799 \mathrm{X}$

ano 7 - número 9 - 2009

liderado pela belgo-francesa Suez e integrado também pela Camargo Corrêa e pela Eletrosul venceu o consórcio da Odebrecht para a construção da hidrelétrica de Jirau. Apesar dos persistentes protestos do consórcio perdedor do leilão em todos os canais possíveis, a Odebrecht acabou admitindo a derrota na disputa. Mas os nacionalistas podem dormir tranqüilos. Mesmo com o fim da política da reserva de mercado, não é essa derrota que vai representar uma limitação ou decadência das empresas de engenharia de origem nacionais, que já constituem um quadro consolidado do grande capital brasileiro no mundo inteiro. 